\title{
EVALUATION OF INTESTINAL BACTERIAL FLORA AND HIV-1 INFECTED INDIVIDUAL'S NUTRITIONAL STATUS, SUPPLEMENTED WITH SOLUBLE FIBER AND PROBIOTIC
}

THESIS: E. B. S. M. Trindade submitted this thesis for his Doctorate in Tropical Diseases at Botucatu School of Medicine, São Paulo State University, UNESP, Botucatu, São Paulo, Brazil, 2004.

Advisor: Professor Paulo Câmara Marques Pereira

ABSTRACT: In the digestive system, there is the presence of bacterial flora which constitutes qualitative and quantitative microorganism diversity in a dynamic host interaction. Intestinal flora obtains its energetic substrates from non-digested diet components or intestinal secretion like mucus, proteins and enzymes. Fermentation is the primary function of the flora colony and has its nutritional, metabolic, immunologic and physical protection implications. This normal intestinal bacterial flora is very stable concerning microorganism presence and the functions it performs, although due to pathological conditions (infection/inflammation), diet composition and nutritional status may alter it. Within infectious processes, HIV-1 infection is emphasized as well as its implications as a possible alteration factor on normal intestinal bacterial flora. Therefore, the aim of this work was to evaluate intestinal bacterial flora and the nutritional status of HIV-1 infected individuals, diseased or not, with a supplement of soluble fibers and probiotic. Thirty-nine adult individuals (19 - 51 years old; $\bar{X}=38$ years), were studied; 26 HIV-1 infected individuals (Male: 07; Female: 19), and 13 non-infected adults (23 - 50 years old; $\bar{X}=37$ years old) as a control group (CG). Infected individuals were distributed into two groups: $\mathrm{G} 1\left(\mathrm{CD}_{4}{ }^{+} \leq 350\right.$ cells $\left./ \mathrm{mm}^{3}\right)$ and $\mathrm{G} 2\left(\mathrm{CD}_{4}{ }^{+}>350\right.$ cells $\left./ \mathrm{mm}^{3}\right)$. All individuals from groups GC, G1 and G2 were evaluated according to body composition (anthropometric), biochemical evaluation and intestinal bacterial flora 
evaluation (Bifidobacterium, Lactobacillus and Bacteroides), at M1 moment, prior to soluble fiber supplementation and probiotic. Groups G1 and G2 were also evaluated at the moments $\mathrm{M} 2$ and $\mathrm{M} 3$ after soluble fiber supplementation and probiotic, respectively. Result analysis showed that the group G1 was different concerning absolute values and statistically different related to $G 2$, concerning Bifidobacterium $(F=7,18 ; p<0,05)$, Lactobacillus $(F=5,57 ; p<0,05)$ and Bacteroides $(F=23,81 ; p<0,05)$, count at the moment $M 1$, the same being similar in every moment (G1: $M 1=M 2=M 3) . \quad G 2$ was statistically different concerning Bifidobacterium $(\mathrm{F}=10,18 ; \mathrm{p}<0,05)$, Lactobacillus $(\mathrm{F}=13,88 ; \mathrm{p}<0,05)$ and Bacteroides $(\mathrm{F}=6,68 ; \mathrm{p}<0,05)$ bacteria, in all the studied moments (G2:M1<[M2=M3]). Related to body and biochemical composition, the groups did not differ statistically, except LDL-cholesterol fraction, group G1 showed difference $(F=7,86 ; p<0,05)$ regarding group $G 2$ at the moment $M 2(M 1<M 2 / F=4,94 ; p<0$, 05). That being so, one can conclude that diet is an important factor on intestinal bacterial flora modulation, once after soluble fiber supplementation and probiotic we observed an quantitative impact, important for intestinal bacterial flora in HIV-1 infected individuals. This project was sponsored by FAPESP.

KEY WORDS: Intestinal bacterial flora, soluble fiber, probiotic, HIV-1, nutritional status.

CORRESPONDENCE TO: E. B. S. M. TRINDADE, Rua Joaquim Barreiro, 143, Vila Nogueira, 18606-150, Botucatu, SP, Brasil, Email: erasmotrindade@hotmail.com 